Review

\title{
The value of disturbance-tolerant cercopithecine monkeys as seed dispersers in degraded habitats
}

\author{
Aurélie Albert $^{\mathrm{a}, *}$, Kim McConkey $^{\mathrm{b}}$, Tommaso Savini ${ }^{\mathrm{a}, \mathrm{c}}$, Marie-Claude Huynen ${ }^{\mathrm{a}}$ \\ ${ }^{a}$ University of Liège, Department of Biology, Ecology and Evolution, Behavioral Biology Unit, 22 Quai Van Beneden, 4020 Liège, Belgium \\ ${ }^{\mathrm{b}}$ School of Natural Sciences and Engineering, National Institute of Advanced Studies, Indian Institute of Science Campus, Bangalore 560 012, India \\ ${ }^{\mathrm{c}}$ Conservation Ecology Program, School of Bioresources and Technology, King Mongkut's University of Technology Thonburi, Bangkok, Thailand
}

\section{A R T I C L E I N F O}

\section{Article history:}

Received 8 May 2013

Received in revised form 9 December 2013

Accepted 10 December 2013

\section{Keywords:}

Cercopithecine

Forest fragmentation

Forest regeneration

Habitat loss

Primates

Seed dispersal

\begin{abstract}
A B S T R A C T
Habitat disturbance has caused a global decline in populations of frugivores, with critical consequences for seed dispersal. Large-seeded plants are especially threatened as they depend on a restricted number of large-bodied dispersers that are vulnerable to extinction and cannot maintain populations in most disturbed habitats. Cercopithecine monkeys are potentially key seed dispersers in disturbed habitats, because of the robustness of some species to disturbance and their ability to disperse large seeds. However, the potential ecological roles of the more disturbance-tolerant species are rarely discussed. This review evaluates the seed dispersal role of cercopithecines in disturbed habitats by investigating their ability to tolerate habitat disturbance, their seed dispersal abilities, and the threats to species survival. Cercopithecines are characterised by ecological flexibility; most species adjust their diet, group size, home range size and, often, feeding methods according to resource availability and habitat structure. Consequently, $79 \%$ of species are tolerant of varying degrees of habitat disturbance. Cercopithecines are often inconsistent seed dispersers, but they have the capacity to disperse many seeds, large seeds and to disperse them across large distances. They may be among the most important frugivores in altered environments in Asia and Africa. However, many disturbance-tolerant cercopithecine species are targeted by local people as pests, which poses a major threat to their conservation. In conclusion, the management of all disturbance-tolerant cercopithecine species should be re-evaluated given their importance in the regeneration of degraded Asian and African habitats.
\end{abstract}

(c) 2013 Elsevier Ltd. All rights reserved.

\section{Contents}

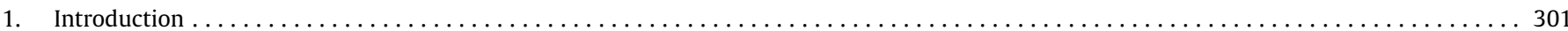

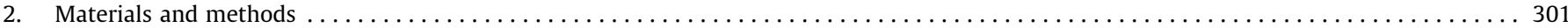

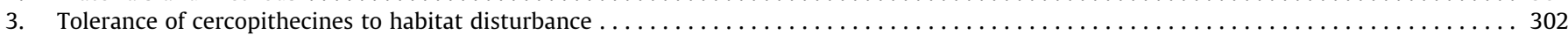

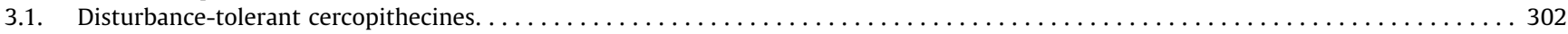

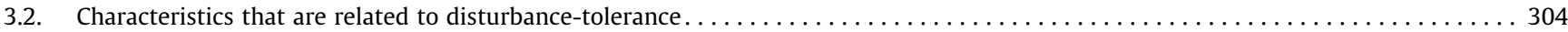

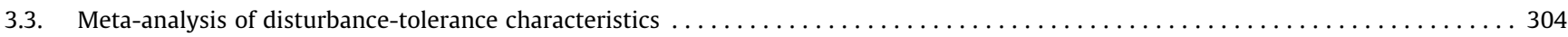

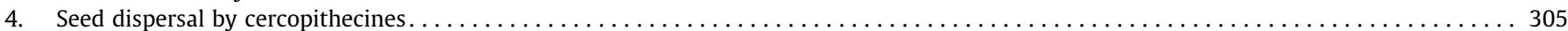

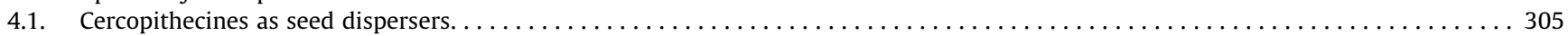

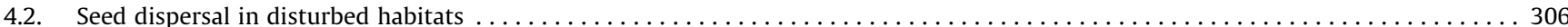

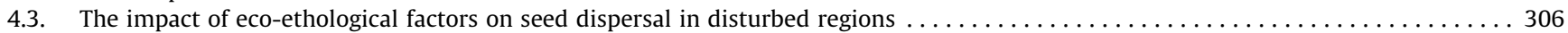

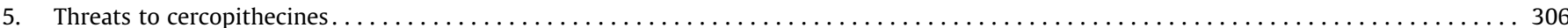

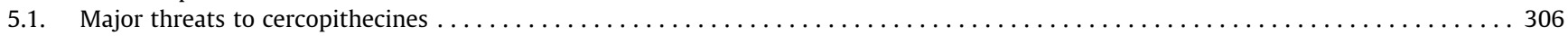

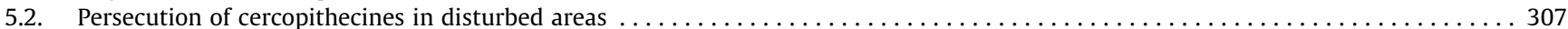

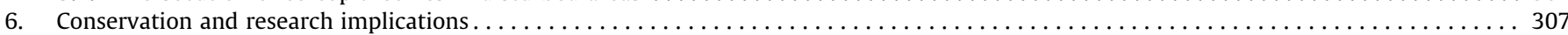

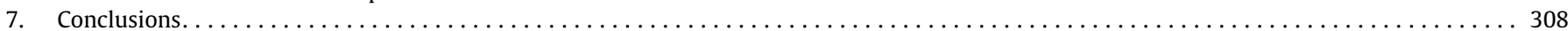

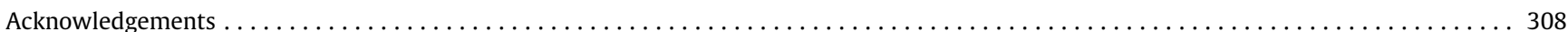

\section{* Corresponding author.}

E-mail addresses: aurelie84.albert@gmail.com (A. Albert), kimmcconkey@yahoo.co.nz (K. McConkey), tommasosavini@gmail.com (T. Savini), marie-claude.huynen@ ulg.ac.be (M.-C. Huynen). 


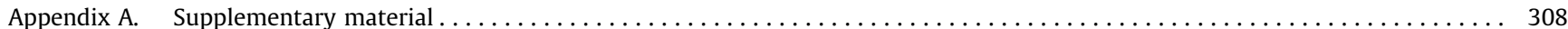

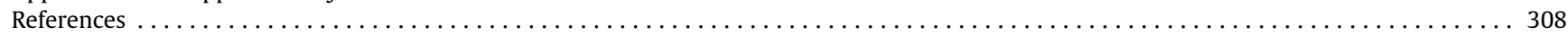

\section{Introduction}

Seed dispersal is a critical process in ecosystem maintenance and recovery, but is negatively impacted by all forms of ecosystem disturbance (McConkey et al., 2012). Decline in frugivore diversity and abundance (Dirzo, 2001) causes a reduction in the quantity of seeds being dispersed, changes in seed dispersal patterns and, ultimately, alteration of plant assemblages (Markl et al., 2012; McConkey et al., 2012; Muller-Landau, 2007). These changes further affect the vulnerability of ecosystems to added threats such as invasive species and climate change (Brook et al., 2008; McConkey et al., 2012). Seed dispersal becomes especially critical for forest regeneration as land degradation becomes more severe and less floristic resources are available (da Silva et al., 1996; Duncan and Chapman, 2002). This problem results partially from the low number of animal-dispersed seeds that are brought into some disturbed areas (Duncan and Chapman, 1999; Vulinec et al., 2006), because the associated low fruit abundance makes them unattractive to potential dispersers (da Silva et al., 1996), and partially from low establishment of dispersed seeds (Balcomb and Chapman, 2003).

The largest frugivores within an ecosystem provide an irreplaceable seed dispersal service, because smaller animals are generally unable to manipulate the large fruits these animals forage on (Babweteera et al., 2007; Campos-Arceiz and Blake, 2011; Forget et al., 2007; Otani, 2010; Tutin et al., 1991). However, these large frugivores are frequently the most vulnerable in disturbed habitats, because of their large or specialised food requirements and/or because they are targeted by hunters (Campos-Arceiz and Blake, 2011; Corlett, 2007; Sethi and Howe, 2009; Stoner et al., 2007). Conservation management of the largest frugivores is confounded by the large tracts of undisturbed habitat these animals require, and populations cannot be maintained in the long term in regions with a high human presence (Hill et al., 2002; Laurance et al., 2006; Naughton-Treves, 1998). For the long-term regeneration of disturbed habitats or maintenance of permanent habitat fragments, it is critical to identify frugivores that can persist in degraded regions and those which are capable of dispersing the larger seeds within these habitats.

Cercopithecine monkeys are one of the most species-rich and broadly distributed subfamilies of primates in the world (Marini et al., 2012). While some species are dependent on undisturbed habitats, others are among the most conspicuous primates in heavily disturbed regions (Biquand et al., 1994; Gross-Camp and Kaplin, 2011; Richard et al., 1989; Rowe and Myers, 2011; Twinomugisha et al., 2006). Cercopithecine monkeys are considered important seed dispersers in many habitats where they have been studied (e.g., tropical forests (Kaplin and Moermond, 1998), temperate forests (Tsujino and Yumoto, 2009), savannas (Slater and du Toit, 2002)). Some species may currently be providing critical services in disturbed habitats in Asia and Africa (Agmen et al., 2010). However, the role of most species is under-appreciated because species that are most tolerant to disturbance are frequently considered to be pests and may be actively persecuted (Hill and Webber, 2010).

The aim in this review was to determine how prevalent disturbance-tolerance was among cercopithecine species, and to evaluate their importance as seed dispersers in disturbed habitats. To achieve the second part of our aim, we reviewed studies on seed dispersal in all habitats and identified behavioural and ecological factors that influence seed dispersal and are potentially modified by disturbance. We asked the following questions: (1) what proportion, and taxa, of cercopithecines are tolerant of different degrees of disturbance? (2) What morphological, behavioural and ecological characters are associated with disturbance-tolerance in cercopithecines? (3) How do these characteristics influence the seed dispersal role of cercopithecines in disturbed habitats? (4) What are the major threats to cercopithecines in disturbed habitats?

\section{Materials and methods}

The tolerance of cercopithecine species to habitat disturbance was assessed from their ability to maintain permanent populations in disturbed habitats, and therefore when using the term "tolerant" in this study, we are making reference to the presence of populations within disturbed habitats. Tolerance ranking was primarily determined from the current IUCN redlist (2013), using the list of habitats occupied. This list notes species that occurred in secondary forests (recorded in our study as low tolerance, T1), rural gardens, plantations, pastures, and heavily degraded former forest (collectively recorded as medium tolerance, T2), and urban areas (high tolerance, T3). Species not recorded in any of these habitats were noted to be intolerant (I). For species recorded in several habitats, the most disturbed habitat occupied served to define the tolerance score. Then, following literature reviews on all species, we altered the tolerance ranking when evidence for a different ranking was found. Since only Cercocebus chrysogaster was noted to be data deficient on the redlist, we assume our rankings are representative of the species' abilities to tolerate disturbance, rather than a function of the data available. A recently described species, Cercopithecus lomamiensis (Hart et al., 2012), currently has no listing on the IUCN Redlist and was not given a tolerance ranking.

Data on eco-ethological characteristics of cercopithecines are presented in Appendix A. These were taken mainly from Rowe and Myers (2011), and Sargis et al. (2008) for locomotion, Murray (1975) for cheek pouch size and use, and Enstam and Isbell (2007) for percentage of fruit in diet. Exhaustive literature reviews were conducted for seed dispersal studies on all cercopithecine species, and for all research conducted in disturbed areas on cercopithecines. We also reviewed studies on the behavioural ecology of cercopithecines to determine what environmental factors influence their behaviour and may have consequences for seed dispersal in disturbed habitats. Data from all accessible studies are reported regardless of study length.

To assess the relative importance of factors determining the tolerance (Intolerant (I), Low (T1), Medium (T2), or High (T3) tolerance) of cercopithecine species, we fitted generalised linear mixed models (GLMM). We first chose traits according to the following criteria: (1) the ability of traits to define the flexibility of a species to changing environmental conditions, (2) data were available for most species, (3) data could be divided into broad categories which encompassed the intra-specific variability that may be present (and is not a function of study length), and (4) data were not a function of study length (e.g., home range size). Thus, traits included in the GLMMs were vegetation type (Forest, Forest + Nonforest, Non-forest (i.e., wetlands, savanna, shrubland, grassland, rocky areas and caves)), locomotion mode (Terrestrial, Semi-terrestrial, Arboreal), predominant diet item (Frugivorous, Folivorous, Faunivorous or Omnivorous when fruit, vegetation and animal matter are all consumed in significant proportions (i.e., over 
20\%)), and intensity of cheek pouch use (Low, Medium, High, following Murray (1975)) of each cercopithecine species. Intraspecific variability prevented the use of other ecological characteristics in the GLMMs, such as home range and group size (although we discuss these traits in relation to disturbance-tolerance generally). We did not include other life history characteristics in the GLMMs because they do not differ significantly amongst cercopithecines, or they are correlated with habitat types (which we included in our analyses) (Marini et al., 2012). We hypothesised that cercopithecines able to live in non-forested habitats, terrestrial or semi-terrestrial, with an omnivorous diet, and able to use their cheek pouches frequently were more likely to be highly tolerant to disturbance (see Section 3.2). We fitted the GLMMs, for each of the cercopithecine traits, using the lme4 package (Bates et al., 2012) in R. We used cercopithecine traits as explanatory variables (i.e., predictors) and genus as a random factor. We calibrated GLMMs with a binomial distribution and a logistic link function (i.e., logit). For predictor selection, we employed a two-step procedure. We first fitted univariate models and then, incorporated significant variables from the univariate models into the multivariate models, with a stepwise selection, so that all independent variables significantly contributed to each final model. We used hypothesis testing because we focused on the significance of independent variables (cercopithecine traits) that explained each response variable (tolerance level). We used $z$-tests (SigmaPlot 11) to compare Asia and Africa in terms of number of disturbance-tolerant species, number of species living in intermediate types of disturbed habitats, number of species able to persist in urban environments, number of disturbance-tolerant species living in secondary forest, and number of threatened species (listed in the IUCN Redlist as vulnerable, endangered, critically endangered; IUCN, 2013). Alpha was set at 0.05 for all analyses and all tests were two-tailed tests.

\section{Tolerance of cercopithecines to habitat disturbance}

\subsection{Disturbance-tolerant cercopithecines}

The family Cercopithecinae includes 12 genera and 69 species (Wilson and Reeder, 2005) (Appendix A). Eleven of these genera are distributed in sub-Saharan Africa (47 species). The remaining genus, Macaca, is one of the most widespread primate genera, with 22 species, ranging from Asia (21 species) to North Africa (1 species). All cercopithecine species live within the tropics (Oates, 1987), except two species (Macaca fuscata and Macaca sylvanus) which are adapted to temperate areas. Most cercopithecine species (43 species) have populations confined to forested habitats, especially Asian species, while 22 species can use both forest and non-forested habitats (i.e., wetlands, savanna, shrubland, grassland, rocky areas and caves) (Fig. 1A). The four remaining species, all in Africa, are found completely in non-forest habitats (Table 1, Appendix A).

Most cercopithecine species (79\%) can live in disturbed habitats (Fig. 1B), while 21\% are intolerant and for one species there is insufficient data (Appendix A). Among cercopithecine species, $15 \%$ (from three genera; Table 1 ) have populations in urban areas (T3) where they forage during the day, and sometimes sleep at night (Richard et al., 1989; Seth et al., 2001); Chlorocebus species are particularly tolerant with four out of six species occurring in urban areas (Table 1). A further $28 \%$ of species can survive in habitats of intermediate disturbance (T2) and secondary forest

\section{(A)}

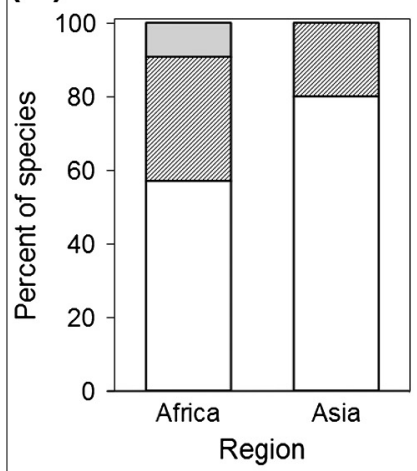

(B)

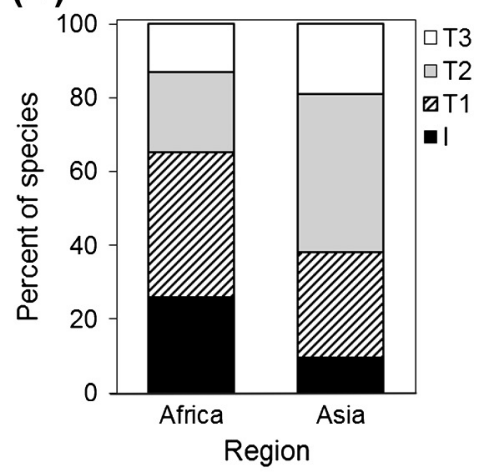

(C)

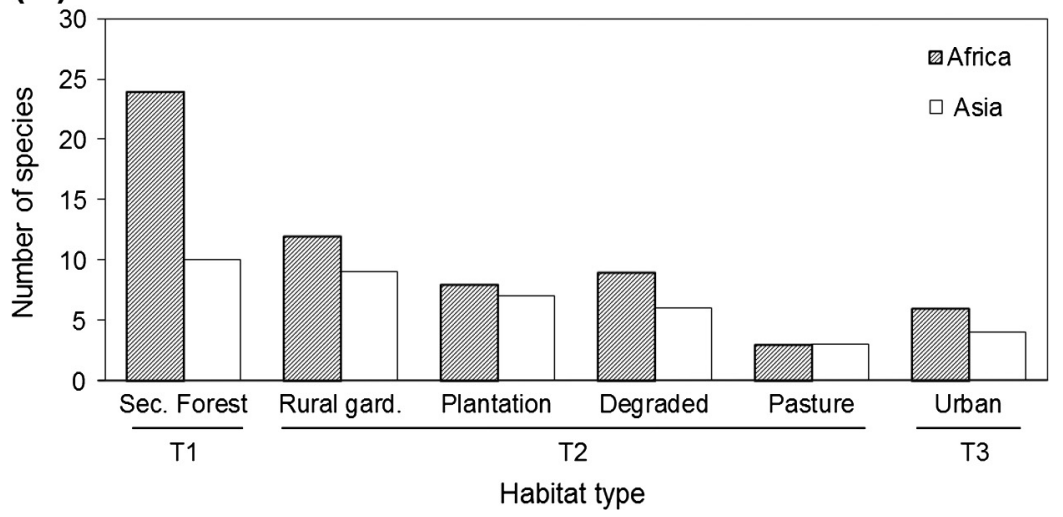

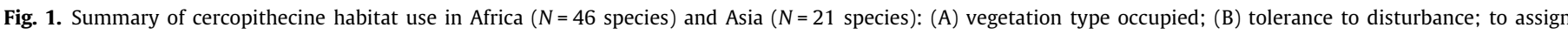

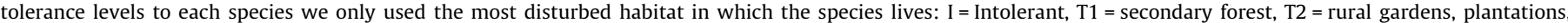

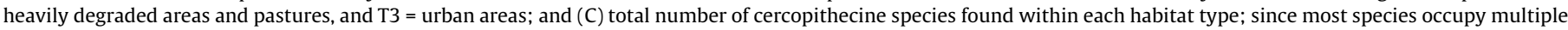
habitats they may be displayed more than once. 
Table 1

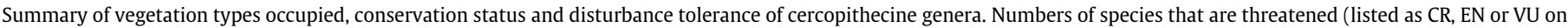

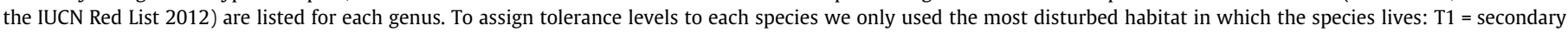

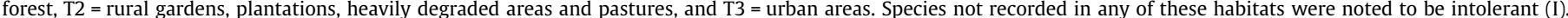

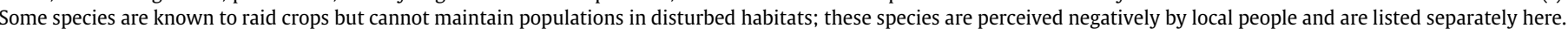

\begin{tabular}{|c|c|c|c|c|c|c|c|c|c|c|}
\hline \multirow[t]{2}{*}{ Genus } & \multirow[t]{2}{*}{ No. of species } & \multicolumn{2}{|c|}{ Vegetation type occupied } & \multirow[t]{2}{*}{ No. of species threatened } & \multicolumn{5}{|c|}{ Tolerance } & \multirow[t]{2}{*}{ Crop raides } \\
\hline & & Single & Multiple & & I & $\mathrm{T} 1$ & $\mathrm{~T} 2$ & T3 & Unknown & \\
\hline \multicolumn{11}{|c|}{ Sub-Saharan Africa } \\
\hline Allenopithecus & 1 & 1 & 1 & 0 & 1 & 0 & 0 & 0 & 0 & 1 \\
\hline Cercocebus & 6 & 6 & 1 & 4 & 2 & 4 & 0 & 0 & 0 & 5 \\
\hline Cercopithecus & 19 & 8 & 3 & 9 & 5 & 8 & 5 & 0 & 1 & 6 \\
\hline Chlorocebus & 6 & 5 & 5 & 1 & 1 & 0 & 1 & 4 & 0 & 3 \\
\hline Erythrocebus & 1 & 1 & 1 & 0 & 0 & 0 & 1 & 0 & 0 & 1 \\
\hline Lophocebus & 2 & 2 & 0 & 0 & 0 & 2 & 0 & 0 & 0 & 1 \\
\hline Mandrillus & 2 & 2 & 1 & 2 & 0 & 2 & 0 & 0 & 0 & 2 \\
\hline Miopithecus & 2 & 2 & 1 & 0 & 0 & 0 & 2 & 0 & 0 & 1 \\
\hline Papio & 5 & 4 & 5 & 0 & 0 & 1 & 3 & 1 & 0 & 5 \\
\hline Rungwecebus & 1 & 1 & 0 & 1 & 1 & 0 & 0 & 0 & 0 & 1 \\
\hline Thercopithecus & 1 & 0 & 1 & 0 & 1 & 0 & 0 & 0 & 0 & 1 \\
\hline \multicolumn{11}{|l|}{ South-east Asia } \\
\hline Macaca & 21 & 21 & 5 & 14 & 3 & 6 & 8 & 4 & 0 & 17 \\
\hline \multicolumn{11}{|l|}{ North Africa } \\
\hline Macaca & 1 & 1 & 1 & 1 & 0 & 0 & 0 & 0 & 0 & 0 \\
\hline
\end{tabular}

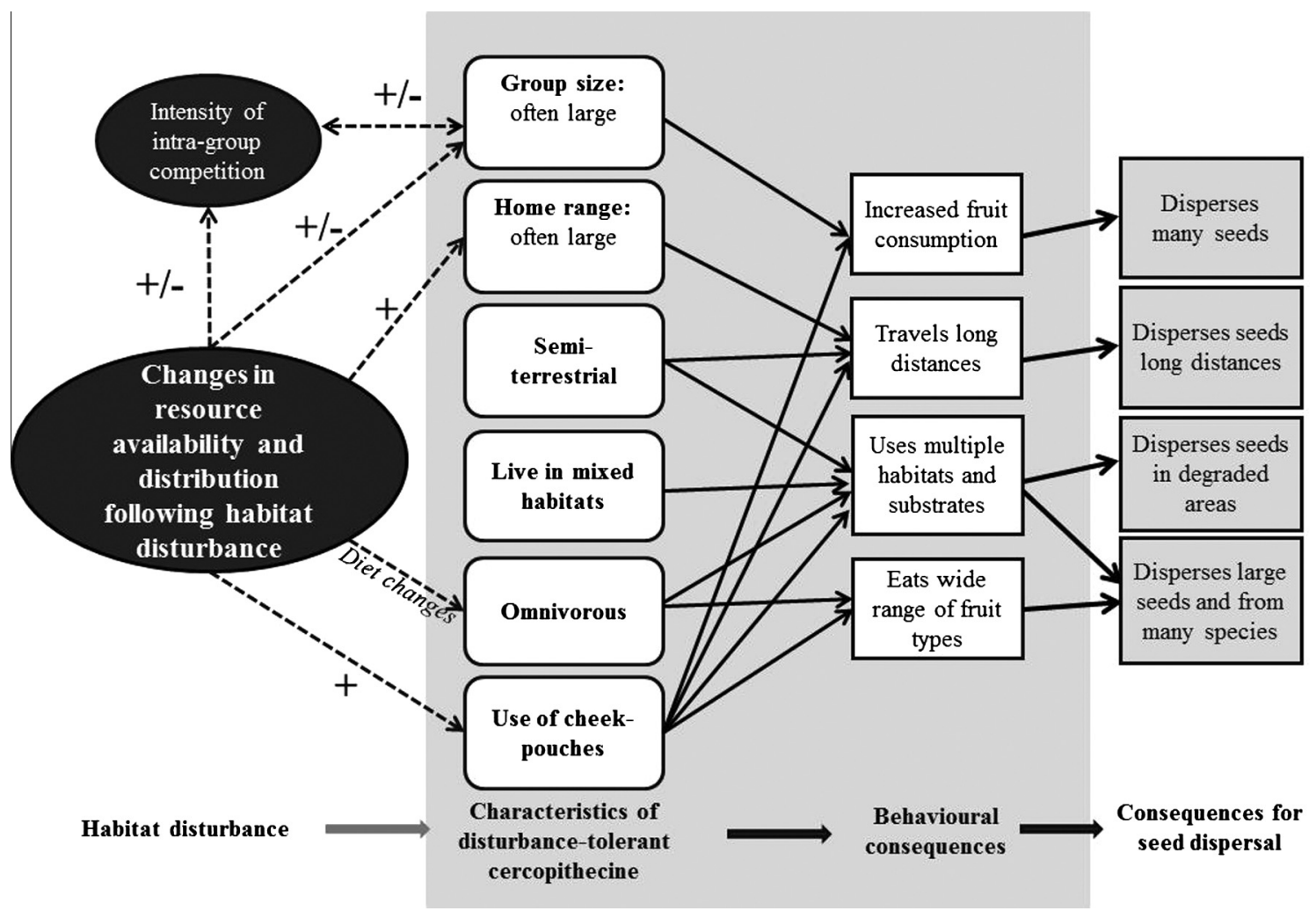

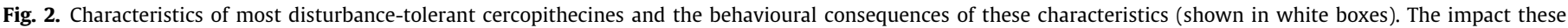

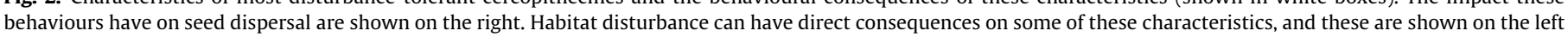
with dotted lines $(+=$ increase, $-=$ decrease $)$.

provides habitat for $36 \%$ of species that are less tolerant to disturbance (T1). Cercocebus is the genus with the highest proportion of intolerant species (Table 1). Cercopithecus, Chlorocebus and Macaca also have some disturbance-intolerant species, and the remaining disturbance-intolerant species are from the specialised genera Allenopithecus, Rungwecebus and Theropithecus (Table 1).

Both Asia (90\% of 21 species) and Africa (74\% of 46 species) have similar proportions of cercopithecines occupying disturbed habitats ( $z$-test, $z=-1.492, p=0.136$ ), but Asian species are significantly more likely to be found in intermediate types of disturbed habitat than African species (T2; $z=-1.765, p=0.040$ ) (Fig. 1B). This may reflect the higher human population density and associated land-use in this region (Corlett and Primack, 2008), or, it may indicate that the single genus (Macaca) found in Asia is particularly well-adapted to these habitats. Most disturbance-tolerant species in Africa are found only in secondary forests (T1) (Fig. 1C), although this figure is statistically comparable to Asian populations $(z=0.792, p=0.430)$ (Fig. 1B). Percentage of 
species able to persist in urban environments is similar in both regions (T3; $z=-0.604, p=0.549$ ) (Fig. 1B). From a habitat perspective, in which each species is recorded in all occupied habitats (rather than the most disturbed habitat occupied), pasture is inhabited by the fewest cercopithecine species, followed by urban areas (Fig. 1C).

\subsection{Characteristics that are related to disturbance-tolerance}

Despite the large diversity of traits encompassed by the cercopithecines (Marini et al., 2012), there are several traits that are common to most taxa and may promote disturbance-tolerance (Fig. 2). In particular, cercopithecines may show a high behavioural and ecological plasticity (i.e., diet, home range, and group size flexibility; Chapman et al., 2002; Marini et al., 2012). This may pre-adapt some cercopithecine species for survival in habitats with altered habitat structure, patchy resource distribution, and limited fruit resources (Isaac and Cowlishaw, 2004).

Dietary flexibility is exhibited by all cercopithecine species but the specialist graminivore, Thecopithecus gelada (Appendix A). While most species preferentially consume fruits or foliage, they are able to adapt their diets according to resource availability (Barrett, 2009; Chapman et al., 2002) and a few species show little specialisation for specific food-types (i.e., Omnivores; Appendix A). This promotes efficient resource use in disturbed habitats and facilitates the consistent use of human food in anthropogenic areas (Brotcorne et al., 2011; Ram et al., 2003).

Flexibility is also shown by the 42 cercopithecine species (62\%) defined as semi-terrestrial, since they are able to consume fruit from all layers of the habitat (Appendix A; Kaplin and Moermond, 1998; Yasuda et al., 2005; Albert, 2012). The remaining species are either completely terrestrial (18\%) or arboreal (19\%). Finally, a significant percentage of cercopithecine species (39\% of 68 species) occupy multiple vegetation types, which may pre-adapt them to using disturbed areas.

Home ranges are variable within most cercopithecine species, inferring high adaptability to habitat conditions. Most home ranges are large ( $71 \%$ of 52 species have populations with home ranges $>100$ ha), or very large ( $21 \%>1000$ ha) (Appendix A), and may vary by factors of 1.2-43 times among populations of the same species $(N=35$ species; mean $=3.3 \times)$. Further, it is the most tolerant species that exhibit the largest variation $(I=4.1 \times, \quad T 1=3.5 \times$, $\mathrm{T} 2=5.8 \times, \mathrm{T} 3=10.3 \times)$. The smallest home ranges are in the genera Cercopithecus and Chlorocebus, and the largest in Papio.

Group sizes are often highly flexible within most cercopithecine species, probably as a response to environmental conditions (Chapman and Chapman, 2000). Maximum recorded group size are frequently large, ranging from 10 to 845 individuals $(N=65$ species; Appendix A), and species with multiple studies have shown variability in group size that may vary by factors of 1.4-50 times (median $=4.2 \mathrm{x} ; N=46$ species). A specific form of fluid group structure, termed fission-fusion dynamics, has been confirmed in at least 11 species (17\%; Appendix A), and may occur in more Macaca species (Barton, 2000; McFarland and Majolo, 2011). Species with a high degree of fission-fusion dynamics change the size of their group according to their activity and the availability and distribution of resources (Amici et al., 2008; Aureli et al., 2008; Chapman and Chapman, 2000). Groups usually split (fission) into smaller subgroups for more efficient use of patchily distributed and temporally varying food sources, and thus to reduce competition, and merge (fusion) where resources are abundant, or at sleeping sites to lower the risk of nocturnal predation (Aureli et al., 2008).

A unifying morphological feature across all cercopithecine species is the presence of cheek pouches (Murray, 1975) and the use of these enables more efficient resource use under stressful conditions (Warren et al., 2011), such as that which occurs in disturbed regions. Whole fruits are stored in the cheek pouches, and then returned singly to the oral cavity where pulp is removed and the seed is spat out. They are used by animals mainly to store fruits while continuing to move, which has beneficial consequences for their ability to exploit fruit crops in stressful conditions (Lambert and Whitham, 2001) as well as for seed dispersal (Lambert, 2005). Most species (72\%) have large cheek pouches they use frequently, while the six species with small cheek pouches use them infrequently (Murray, 1975; Appendix A). Animals are more likely to store food in their cheek pouches under conditions of intense intra-group competition (Lambert and Whitham, 2001), or predation risk (Smith et al., 2008), such as in disturbed areas with a high human presence (Warren et al., 2011). Crop raiding by some cercopithecines is widespread in both Asia and Africa (Naughton-Treves, 1998; Priston, 2005; Saj et al., 2001; Weyher et al., 2006; Wieczkowski, 2005) (Table 1, Appendix A) and cheek pouches provide a direct advantage to raiding animals because they can store food within the cheek pouches quickly, and retreat to a safer location to consume it (Warren, 2008). Baboons used their cheek pouches significantly more often when raiding crops (Warren, 2008), and also when provisioned by humans, probably to cope with high levels of intra-group competition (Lambert and Whitham, 2001).

\subsection{Meta-analysis of disturbance-tolerance characteristics}

Six ecological traits associated with adaptability, and therefore disturbance-tolerance, were identified using the data we gathered on each cercopithecine species: a diet not dominated by fruit, use of multiple vegetation types, semi-terrestrial locomotion, frequent use of cheek pouches, large and variable home ranges and variable group size. Intolerant species had the lowest incidence of these traits (median number of traits displayed by each species $=2.5$; $21 \%$ of species had at least half of the traits) and highly tolerant species had the highest incidence (median $=6 ; 87 \%$ ). T1 and T2 displayed an intermediate number of these traits (medians $=3.5$ and 3; $50 \%$ and $33 \%$, respectively).

GLMMs were developed for each tolerance level (T1-3) for four of these traits (home range and group size variables were not included; see methods). Two models (T1 and T3) showed an association between one selected cercopithecine trait and tolerance level. A low tolerance to habitat disturbance (T1) was positively associated with occupying forest only (coefficient: $1.735 \pm 0.698$; $p$-value $=0.013$ ). A high tolerance to disturbance (T3) was positively associated with occupying multiple vegetation types (e.g., Forest + Non-forest) (coefficient: $2.011 \pm 1.016 ; \quad p$-value $=0.048)$ and negatively associated with a fruit-dominated diet (coefficient: $-2.813 \pm 1.024 ; p$-value $=0.006$ ). These results suggest that forestdependent cercopithecines are likely to be less tolerant to disturbance, contrary to those able to live in multiple vegetation types. Moreover, cercopithecines whose diet is not dominated by fruits are more likely to be tolerant.

These results support the idea that the high flexibility of some cercopithecine species infers greater tolerance to disturbance. The flexibility in the behaviour and ecology of the most tolerant species enables them to adapt their home range size, location and their diet to habitat disturbance (Tutin et al., 1997; Twinomugisha et al., 2006), and they can even exploit resources made available through human activities (Boulton et al., 1996; Ram et al., 2003). On the contrary, some species depend highly on forest, probably due to their arboreal habits or their reliance on specific dietary items. The ability of many cercopithecine species to tolerate disturbance has important consequences for their function as seed dispersers into or across disturbed habitats (Fig. 2). 
Table 2

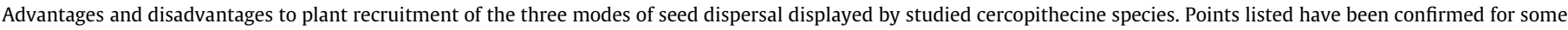
species of primates, including cercopithecine species, and are likely to be applicable to more cercopithecines.

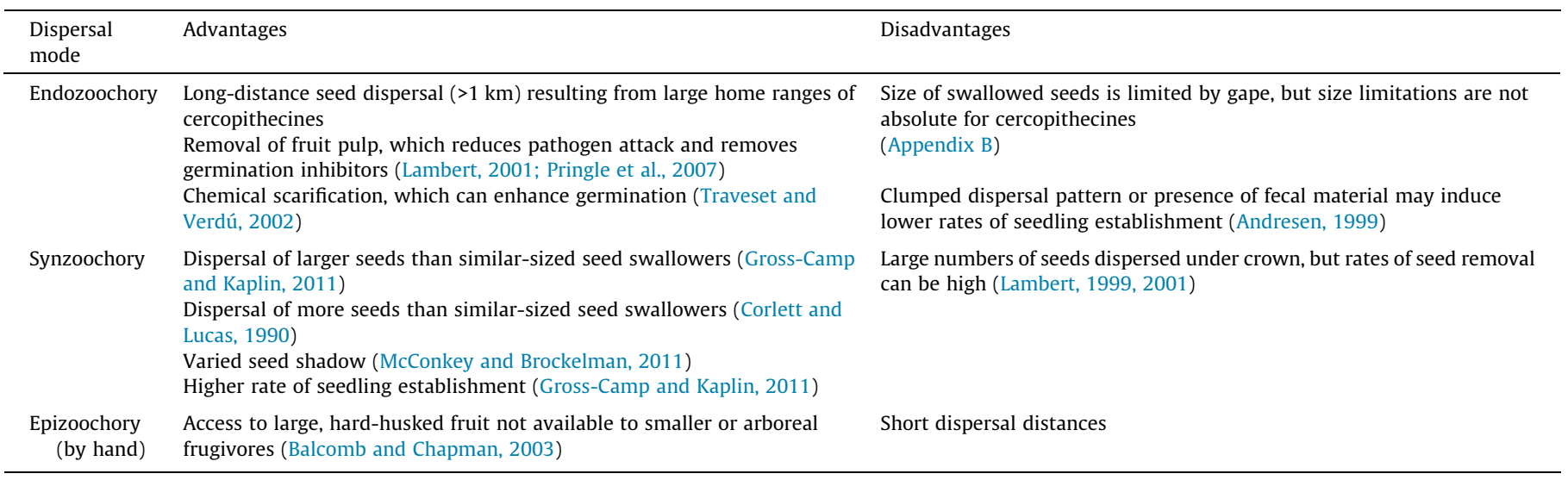

\section{Seed dispersal by cercopithecines}

\subsection{Cercopithecines as seed dispersers}

Cercopithecines are unique among primates because they disperse seeds in three different ways (Yumoto et al., 1998): epizoochory (dispersal via the outside of the animal, e.g., by dropping), endozoochory (dispersal by swallowing and defecation) and synzoochory (dispersal by storing fruit in cheek pouches and spitting seeds out). They alternate these seed processing techniques according to phenology patterns, plant species and resource availability (Kaplin and Moermond, 1998; Tsujino and Yumoto, 2009), and may even use various deposition patterns for the same plant species (Albert, 2012; Lambert and Garber, 1998). This creates a unique seed shadow, which could have positive consequences for seed survival (Gross-Camp and Kaplin, 2005; Schupp et al., 2010; Stoner et al., 2007). Research on the seed dispersal capabilities of cercopithecines is available for 21 species (31\% of all species; Appendix B).

Seed swallowing, and subsequent deposition in the feces, is usually considered the most advantageous form of handling for seed recruitment (Table 2) (Chapman and Russo, 2007; Lambert, 2002b). Physical limitations of gape size constrains the seed sizes that can be swallowed by primates, but animal behaviour and fruit characteristics also determine whether a seed will be swallowed or dropped (Lambert and Garber, 1998). In cercopithecines, swallowed seeds tend to be smaller than spat-out seeds (Lambert, 1999; Lucas and Corlett, 1998) (Appendix B) but recorded seed size limitations of most cercopithecines are not absolute. As seed size increases, the animals tend to swallow fewer seeds and spit more, thereby still dispersing a small number of large seeds by defecation (Kaplin and Lambert, 2002; Kaplin and Moermond, 1998; Otani, 2010; Poulsen et al., 2001; Yumoto et al., 1998). The largest seed recorded being swallowed for each species $(N=8)$ is significantly related to body size (Pearson's correlation: $r=0.792, p=0.02$ ) with seeds as long as $42 \mathrm{~mm}$ being swallowed by Mandrillus leucophaeus (Astaras and Waltert, 2010) the largest cercopithecine (Appendix B). In fact, some larger cercopithecine taxa are able to disperse by endozoochory seeds of a comparative size range as apes (Kunz and Linsenmair, 2008).

The ability of cercopithecines to swallow a range of seed sizes is important, because they are potentially good long-distance seed dispersers. Dispersal distances are a product of the gut retention time of the animal and the distance they travel during this period. Cercopithecines have among the longest gut retention times across the primate order (Appendix B) (Lambert, 1998, 2002a) and can cover relatively long distances daily
(200-13,000 m/day, with most populations travelling more than $1000 \mathrm{~m} /$ day) (Appendix A). Hence, their ability to move seeds long distances is potentially comparable with other large-bodied seed dispersers such as elephants (Campos-Arceiz et al., 2008) and hornbills (Holbrook and Smith, 2000) and increases the probability for seeds to be dispersed in different habitats than from where they were ingested.

The use of cheek-pouches and subsequent seed-spitting by cercopithecines has been considered an inefficient form of seed dispersal. It frequently results in large numbers (>80\%) of seeds deposited under or close to the crown of the parent plant, where rates of seed predation and seedling competition are often high (Lambert, 1999, 2001). More recent studies, however, suggests this unique mode of dispersal may often have key advantages for seed recruitment (Table 2). First, cheek-pouch use allows even smallerbodied cercopithecines to disperse large-seeded species, and they can potentially disperse larger seeds than seed-swallowing primates (e.g., the average size dispersed is $25 \mathrm{~mm}$ in Cercopithecus lhoesti vs $15 \mathrm{~mm}$ in Pan troglodytes schweinfurthii; Gross-Camp and Kaplin, 2011). Second, when animals do not swallow seeds, which would be inert bulk in their gut, they can potentially consume many more seeds than seed swallowing primates (Corlett and Lucas, 1990; Lambert, 1999; McConkey and Brockelman, 2011). Third, the rate of seedling establishment for spat seeds of some plant species has been found to be higher than for defecated seeds (Balcomb and Chapman, 2003; Gross-Camp and Kaplin, 2011) and seeds dropped by birds and bats (Kankam and Oduro, 2012). Fourth, high removal rates of seeds from the vicinity of the parent plant have now been documented for some plant species dispersed by Macaca (>80\%; McConkey et al. unpublished data), and distances of several hundred metres have been recorded for spat seeds (Huang, 2005; Appendix B). Finally, when cercopithecines both spit and defecate seeds of the same species the resulting variability in the seed shadow can be beneficial to a plant, because seeds reach a wider variety of regions and distances (McConkey and Brockelman, 2011; Poulsen et al., 2001).

The largest fruits processed by cercopithecines are transported in the hands (Table 2). While most seeds are dropped at short distances from the parent plant, longer distances have been recorded (e.g., $130 \mathrm{~m}$ for a Mangifera indica seed by Macaca leonina; Albert et al., 2013). The dexterity of cercopithecines and their frequently terrestrial life-styles, leaving their hands free to hold fruits, means they can access seeds in large, hard-husked fruits that are unavailable to smaller, or primarily arboreal, primates (Balcomb and Chapman, 2003). Consequently, they have been recorded dispersing seeds from fruits primarily dispersed by elephants, albeit less efficiently (Nakashima et al., 2008). 


\subsection{Seed dispersal in disturbed habitats}

Looking at the different cercopithecine genera, most research on seed dispersal by cercopithecines in disturbed habitats has been limited to less tolerant (T1) species of Cercopithecus (Chapman and Onderdonk, 1998; Gross-Camp and Kaplin, 2011; Kirika, 2007), with a few studies on Papio (T2-T3; Duncan and Chapman, 2002; Reinhardt and Rossouw, 2000; Slater and du Toit, 2002), Chlorocebus (T3; Agmen et al., 2010) and Macaca (T3; Tsuji, 2011) in more disturbed habitats. Studies on seed dispersal by highly tolerant (T3) cercopithecines in a diversity of disturbed habitats are almost completely lacking.

Studies on Cercopithecus have focused on their occupation of forest fragments and movements between them. Only C. lhoestii has been documented dispersing seeds into disturbed habitats (Gross-Camp and Kaplin, 2011); however, several other species have been reported to use good quality forest fragments or move between fragments (Cercopithecus ascanius, Cercopithecus cephus, Cercopithecus nictitans, Cercopithecus mitis, Cercopithecus mona; Chapman et al., 2002; Chapman and Onderdonk, 1998; Kaplin and Moermond, 1998; Kirika, 2007; Stickler, 2004; Thomas, 1991) and probably disperse seeds within fragments or the matrix surrounding fragments. Lophocebus albigena has also been reported consuming fruit in heavily disturbed regions (Kirika, 2007).

Papio species vary in their tolerance to habitat disturbance, but they are considered effective dispersers because they transport seeds over long distances and across a variety of habitats (Kunz and Linsenmair, 2008) and have been documented dispersing primary forest tree species into logged plantations (Duncan and Chapman, 2002). In savanna habitats, they are among the few dispersers that can disperse seeds across fence lines (Slater and du Toit, 2002) and are considered principal dispersers of several invasive plant species (Mworia et al., 2011; Reinhardt and Rossouw, 2000).

The genus Chlorocebus has the largest proportion of highly tolerant species (T3; see Section 3.1). However seed dispersal studies have only been conducted on one species, Chlorocebus tantalus, in a mosaic of fragmented forest and degraded grasslands in Nigeria (Agmen et al., 2010). The studied population regularly used degraded regions and $C$. tantalus was considered to be an important disperser of forest edge species into grasslands; all scats contained seeds, from 12 plant species.

Macaca are the largest frugivores in many highly-disturbed Asian habitats and may consume a wide range of fruit types (Corlett, 2011), but their role in seed dispersal in these habitats has rarely been investigated. The only published study is on M. fuscata inhabiting intercity forests in Tokyo. Preliminary evidence suggests they disperse a similar diversity of fruit as in less-disturbed habitats, with $85 \%$ of scats containing seeds of 20 plant species (Tsuji, 2011).

\subsection{The impact of eco-ethological factors on seed dispersal in disturbed regions}

Animal behaviour has direct consequences for seed deposition (i.e., seed shadow; Nathan and Muller-Landau, 2000). Therefore, the behavioural and ecological flexibility displayed by many cercopithecine species, will influence their seed dispersal function within disturbed habitats (Fig. 2). The few studies that have been conducted on changes in cercopithecine behaviour and ecology in disturbed habitats indicate alterations in diet (Chapman et al., 2002), foraging and movement patterns (Stickler, 2004), and group size (Fukuda, 2004; Menon and Poirier, 1996; Singh et al., 2002; Singh and Vinathe, 1990), and all these factors directly impact seed deposition.
Intra-specific feeding competition is among the most important determinants of fruit handling behaviour, and subsequent seed deposition patterns in cercopithecines, because it promotes cheek pouch use, and encourages individuals to move away from the food source to process fruits and deposit seeds (Lambert, 2005; Smith et al., 2008). The intensity of competition between individuals is influenced by habitat quality, resource distribution and troop size, and consequently may change for cercopithecine populations inhabiting disturbed habitats. While larger troops have a greater number of competitors (Murray, 1975; Oates, 1987), the impact of troop size on fruit handling is relative to the abundance and distribution of resources. In habitats with patchily distributed, high quality, resources (e.g., forests), competition among individuals can be intense and cheek pouch-use more frequent (Lambert, 2005), particularly in larger food patches because sub-groups are less likely to occur (Aureli et al., 2008). In smaller food patches, fission of the social unit may occur, which precludes an increase in competition (Aureli et al., 2008; Chapman and Chapman, 2000; Fukuda, 1989). Permanent group fission and dispersal of individuals occurs in some Macaca species in degraded areas where there is a shortage of natural foods (Dittus, 1988; Fukuda, 2004), although for some species group size increases have been recorded (Menon and Poirier, 1996; Singh et al., 2002; Singh and Vinathe, 1990). These increases may be due to the availability of human food, such as crops or food provisioning, compensating for the reduced fruit abundance (Brotcorne et al., 2011; Menon and Poirier, 1996; Singh et al., 2002; Singh and Vinathe, 1990). Competition among cercopithecines could increase or decrease in degraded areas; a small decrease in resources initiating group fission could decrease competition, while a severe decrease in resource availability may increase competition. This is an important response to disturbance that is under-studied in cercopithecines and has direct consequences for their seed dispersal function (Fig. 2). In habitats where competition increases, the proportion of seeds dispersed and seed dispersal distances are likely to increase, while the opposite may occur in habitats where competition decreases.

Fruit abundance and distribution have important implications for diet, seed handling behaviour and movements of cercopithecines, with direct consequences for seed dispersal in disturbed regions (Fig. 2). When overall fruit supplies are low, which more commonly occurs in disturbed regions (Johns and Skorupa, 1987), some species reduce overall fruit consumption (e.g., Cercopithecus; Chapman et al., 2002) or switch from being seed swallowers and spitters to seed predators (Gautier-Hion et al., 1993; Kaplin and Moermond, 1998; Poulsen et al., 2002). However, the preference of most cercopithecines for fruit means they may travel long distances (even in disturbed areas) to exploit favoured items (Stickler, 2004) and may remain effective dispersers for the fruit species that are available. In Macaca populations that exploited scattered resources across heterogeneous habitats, groups travelled between high concentrations of a given fruiting plant species, thereby dispersing seeds within the specifically suitable habitat in which the con-specific adult trees are distributed, which may be beneficial for recruitment (Tsujino and Yumoto, 2009). The dietary flexibility of most cercopithecines and diffuse foraging patterns mean they revisit fruiting trees less frequently than many efficient frugivores, but disperse seeds more widely (Clark et al., 2004) and may disperse more seed species (Clark et al., 2001).

\section{Threats to cercopithecines}

\subsection{Major threats to cercopithecines}

Half the cercopithecine species (48\%) are threatened (listed in the IUCN Redlist as vulnerable, endangered, critically endangered; 
(A)

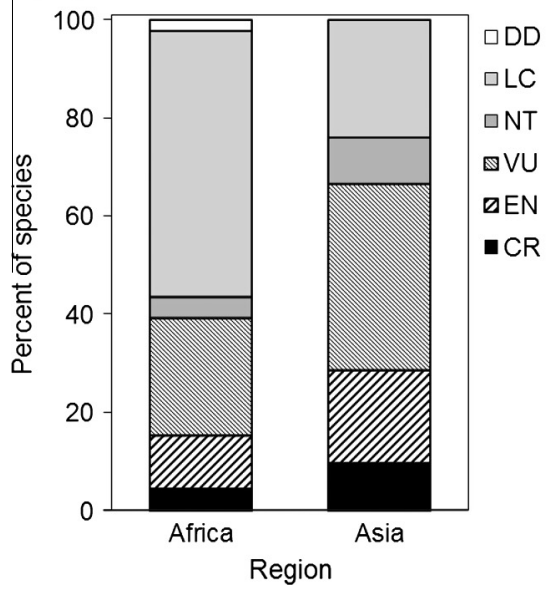

(B)

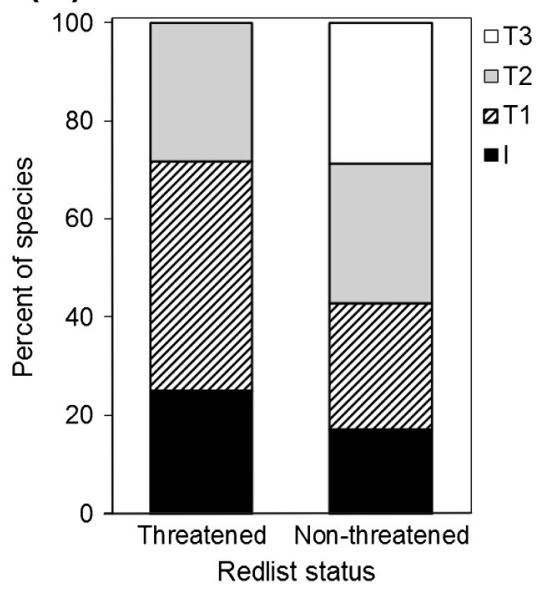

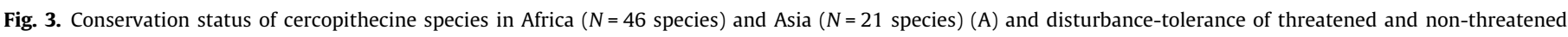

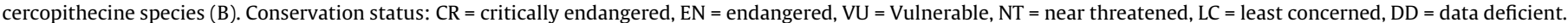

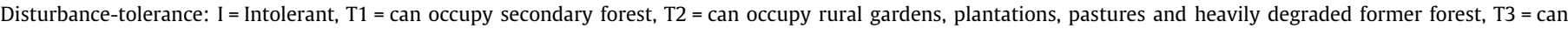

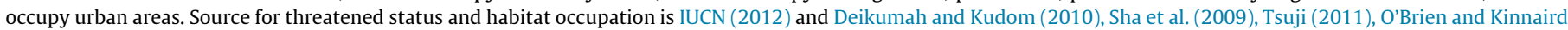
(1997), Riley and Priston (2010), Dittus (1977), Maisels et al. (2006), and Hoffman and O'Riain (2011).

IUCN, 2012) (Table 1, Appendix A), with nearly twice as many species considered to be threatened in Asia (67\%) than in Africa (39\%) ( $z$-test, $z=2.129, P=0.033$ ) (Fig. 3 ). In both regions habitat loss and hunting are the primary threats; in Africa $64 \%$ of species are threatened with habitat loss and $51 \%$ hunting, while in Asia $71 \%$ of species are threatened with both habitat loss and hunting. Persecution is also a major threat, particularly in Asia (48\%; Africa 24\%). Some cercopithecine species currently have no major threats $(29 \%$ in Africa, $10 \%$ in Asia).

All the highly tolerant cercopithecine species (T3) are not threatened and are generally of low conservation priority (Fig. 3). Cercopithecine species that have medium or low tolerance to disturbance are almost equally divided between a threatened and non-threatened status, but the threatened species are frequently targets for hunters or are persecuted as pests (IUCN, 2013). Hence, for cercopithecine species that are tolerant of habitat disturbance and could be important seed dispersers in such environments, targeted hunting (for food or as pest control) is the major threat to their survival. Insufficient food resources also have consequences for cercopithecines in disturbed habitats; some forest fragments in eastern Africa were noted to be of insufficient quality to support permanent populations of species of medium tolerance (Swart and Lawes, 1996; Worman and Chapman, 2006).

\subsection{Persecution of cercopithecines in disturbed areas}

Human population growth brings humans and wildlife into direct competition within an increasingly overlapping niche (Priston, 2005; Sillero-Zubiri and Switzer, 2001). Crop raiding has been widely documented among cercopithecines (26 species, $57 \%$ of species in sub-Saharan Africa, and 13 species, 62\% in Asia), even among species that are not able to establish permanent populations in degraded areas ( 8 species) (Appendix A). Indeed their intelligence, the ability of most species to travel quickly on the ground and their cheek pouch use (enabling them to store more food) make them successful crop-raiders (Warren, 2008). The invasion of agricultural and urban areas by cercopithecines is a result of increased urban development (Biquand et al., 1994), natural or human-induced reduction in food supplies in less disturbed areas (Fukuda, 2004; Riley, 2007), increased foraging efficiency in agricultural areas and/or local extinction of the natural predators of cercopithecines (Warren et al., 2011).

Agonistic interactions between cercopithecines and humans in agricultural areas and cities (Chauhan and Pirta, 2010; Richard et al., 1989) frequently lead to a negative perception of the monkeys by local people. Even in forested areas there frequently exists a high overlap between important food species in cercopithecine and human diets, and therefore negative interactions between them (Kinnaird, 1994; Riley, 2007). However, there is often a mismatch between damage inflicted by animals (e.g., during crop raiding) and that reported or perceived to occur (Lee and Priston, 2005; Riley, 2007). In particular, species that occur in large groups and are visually intimidating are most frequently likely to be perceived as a serious pest, regardless of the amount of damage caused (Hill, 2000; Riley, 2007). This negative perception poses a major threat to their conservation (Hill and Webber, 2010; Lee and Priston, 2005). The lethal control of "pests" has caused the extinction of several animal species (Woodroffe et al., 2005) and cercopithecines are frequently killed in retaliation for raiding (Boulton et al., 1996; IUCN, 2013; Priston, 2005; Richard et al., 1989; Strum, 2010).

\section{Conservation and research implications}

The small number of studies documenting seed dispersal by cercopithecines in disturbed habitats is unlikely to reflect the occurrence of such seed dispersal events, but rather the perception that such events are unimportant. Neither seed dispersal studies nor primate ecological studies in highly disturbed habitats have been a research priority in much of Africa and Asia. However, in this review we show that many cercopithecine taxa are preadapted to exploiting scattered resources and adjusting their diet according to resource availability. With their long gut passage times and long travel distances, cercopithecines are likely to be regularly dispersing seeds across fragments and into or within degraded areas (Corlett, 1998; Duncan and Chapman, 2002). The pre-adaptations that promote dispersal-tolerance in some cercopithecine species, however, may also alter their seed dispersal role in these habitats. It is critical we improve our understanding of seed dispersal by cercopithecines in disturbed habitats, particularly for those species directly persecuted by humans. Further, the conservation status of all disturbance-tolerant cercopithecines 
should be reviewed to account for important ecological role they may play.

\section{Conclusions}

Nearly $80 \%$ of cercopithecine species can live in disturbed habitats and most of these species are potentially important seed dispersers into, within and across these habitats. Because of their large intra-specific flexibility with respect to diet, locomotion, vegetation type occupied and group size, many species have the capacity to adapt to heterogeneous habitat conditions, such as those associated with disturbance. Cheek-pouch use by cercopithecines enables them to disperse large seeds and many seeds, while large daily ranges promote long distance dispersal events. Consequently, cercopithecines are potentially among the most effective seed dispersers in disturbed habitats in Africa and Asia. However, changes in behaviour and ecology as a consequence of disturbance may modify their role. As habitat disturbance accelerates in Asia and Africa, it is critical to identify which seed dispersal agents can persist in the altered environments and to determine their capacity for seed dispersal in these disturbed habitats (McConkey et al., 2012). Many cercopithecine species are excellent examples of potentially important seed dispersal agents that have not been considered a high priority for studies in most regions, particularly in disturbed Asian habitats.

The major threat to the survival of disturbance tolerant cercopithecines is direct hunting - for food or as a measure of pest reduction. For cercopithecine species that are currently threatened, such threats are considered to be serious and solutions to the negative perception of cercopithecines are sought (Riley et al., 2011). However, it is critical that the management of all disturbance-tolerant species be re-evaluated - not only the threatened species - since their conservation could be the first step to the regeneration of degraded Asian and African habitats (Lambert, 2010).

\section{Acknowledgements}

We thank Lee Olsen, David Chivers, and four anonymous reviewers for their valuable comments on previous drafts of this manuscript.

\section{Appendix A. Supplementary material}

Supplementary data associated with this article can be found, in the online version, at http://dx.doi.org/10.1016/j.biocon. 2013. 12.016 .

\section{References}

Agmen, F.L., Chapman, H., Bawuro, M., 2010. Seed dispersal by tantalus monkeys (Chlorocebus tantalus tantalus) in a Nigerian montane forest. Afr. J. Ecol. 48, $1123-1128$.

Albert, A., 2012. Feeding and ranging behavior of northern pigtailed macaques (Macaca leonina): impact on their seed dispersal effectiveness and ecological contribution in a tropical rainforest at Khao Yai National Park, Thailand. Département de Biologie, Ecologie et Environnement, Université de Liège, Liège, Belgium, p. 220.

Albert, A., Hambuckers, A., Culot, L., Savini, T., Huynen, M.-C., 2013. Frugivory and seed dispersal by Northern pigtailed macaques (Macaca leonina), in Thailand. Int. J. Primatol. 34, 170-193.

Amici, F., Aureli, F., Call, J., 2008. Fission-fusion dynamics, behavioral flexibility, and inhibitory control in primates. Curr. Biol. 18, 1415-1419.

Andresen, E., 1999. Seed dispersal by monkeys and the fate of dispersed seeds in a Peruvian rain forest. Biotropica 31, 145-158.

Astaras, C., Waltert, M., 2010. What does seed handling by the drill tell us about the ecological services of terrestrial cercopithecines in African forests? Anim. Conserv. 13, 568-578.

Aureli, F., Shaffner, C., Boesch, C., Bearder, S., Call, J., Chapman, C., Connor, R., Di Fiore, A., Dunbar, R.I.M., Henzi, S.P., Holekamp, K., Korstjens, A.H., Layton, R., Lee, P.C., Lehmann, J., Manson, J.H., Ramos-Fernández, G., Strier, K.B., van Schaik, C.P.,
2008. Fission-fusion dynamics: new research frameworks. Curr. Anthropol. 49, 627-654.

Babweteera, F., Savill, P., Brown, N., 2007. Balanites wilsoniana: regeneration with and without elephants. Biol. Conserv. 134, 40-47.

Balcomb, S.R., Chapman, C.A., 2003. Bridging the gap: influence of seed deposition on seedling recruitment in a primate-tree interaction. Ecol. Monogr. 73, 625642 .

Barrett, A.S., 2009. Spatial and temporal patterns in resource dispersion and the structure of range use and co-existence in a social omnivore Chlorocebus aethiops. Environmental Management, University of South Africa, p. 290.

Barton, R.A., 2000. Socioecology of baboons: the interaction of male and female strategies. In: Kappeler, P.M. (Ed.), Primate males: causes and consequences of variation in group composition. Cambridge University Press, Cambridge, pp. 97-107.

Bates, D., Maechler, M., Bolker, B., 2012. Ime4: Linear mixed-effects models using S4 classes.

Biquand, S., Boug, A., Biquand-Guyot, V., Gautier, J.P., 1994. Management of commensal baboons in Saudi Arabia. Revue d'Ecologie 49, 213-222.

Boulton, A.M., Horrocks, J.A., Baulu, J., 1996. The Barbados vervet monkey (Cercopithecus aethiops sabaeus): changes in population size and crop damage, 1980-1994. Int. J. Primatol. 17, 831-844.

Brook, B.W., Sodhi, N.S., Bradshaw, C.J.A., 2008. Synergies among extinction drivers under global change. Trends Ecol. Evol. 23, 453-460.

Brotcorne, F., Wandia, I.N., Rompis, A.L.T., Soma, I.G., Suartha, I.N., Huynen, M.C. 2011. Recent demographic and behavioural data of Macaca fascicularis at Padangtegal, Bali (Indonesia). In: Gumert, M.D., Fuentes, A., Jones-Engel, L. (Eds.), Monkeys on the Edge: Ecology and Management of Long-Tailed Macaques and their Interface with Humans. Cambridge University Press, Cambridge, pp. 180-183.

Campos-Arceiz, A., Blake, S., 2011. Megagardeners of the forest - the role of elephants in seed dispersal. Acta Oecol. 37, 542-553.

Campos-Arceiz, A., Larrinaga, A.R., Weerasinghe, U.R., Takatsuki, S., Pastorini, J. Leimgruber, P., Fernando, P., Santamaría, A.L., 2008. Behavior rather than diet mediates seasonal differences in seed dispersal by Asian elephants. Ecology 89, 2684-2691.

Chapman, C.A., Chapman, L.J., 2000. Determinants of group size in primates: the importance of travel costs. In: Boinski, S., Garber, P. A (Eds.), On the Move: How and Why Animals Travel in Groups. University of Chicago Press, Chicago, pp. 24-42.

Chapman, C.A., Onderdonk, D.A., 1998. Forests without primates: primate/plant codependency. Am. J. Primatol. 45, 127-141.

Chapman, C.A., Russo, S.E., 2007. Primate seed dispersal: linking behavioral ecology with forest community structure. In: Campbell, C.J., Fuentes, A.F., MacKinnon, K.C., Panger, M., Bearder, S. (Eds.), Primates in Perspective. Oxford University Press, Oxford, pp. 510-525.

Chapman, C.A., Chapman, L.J., Cords, M., Gathua, J.M., Gautier-Hion, A., Lambert, J.E., Rode, K., Tutin, C.E.G., White, L.J.T., 2002. Variation in the diets of Cercopithecus species: differences within forests, among forests, and across species. In: Glenn, M.E., Cords, M. (Eds.), The Guenons: Diversity and Adaptation in African Monkeys. Kluwer Academic/Plenum Publishers, New York, pp. 325-350.

Chauhan, A., Pirta, R.S., 2010. Agonistic interactions between humans and two species of monkeys (rhesus monkey Macaca mulatta and hanuman langur Semnopithecus entellus) in Shimla, Himachal Pradesh. J. Psychol. 1, 9-14.

Clark, C.J., Poulsen, J.R., Parker, V.T., 2001. The role of arboreal seed dispersal groups on the seed rain of a lowland tropical forest. Biotropica 33, 606-620.

Clark, C.J., Poulsen, J.R., Connor, E.F., Parker, V.T., 2004. Fruiting trees as dispersal foci in a semi-deciduous tropical forest. Oecologia 139, 66-75.

Corlett, R., 1998. Frugivory and seed dispersal by vertebrates in the oriental (Indomalayan) region. Biol. Rev. 73, 413-448.

Corlett, R., 2007. The impact of hunting on the mammalian fauna of tropical Asian forests. Biotropica 39, 292-303.

Corlett, R.T., 2011. Seed dispersal in Hong Kong, China: past, present and possible futures. Integr. Zool. 6, 97-109.

Corlett, R., Lucas, P.W., 1990. Alternative seed-handling strategies in primates: seed-spitting by long-tailed macaques (Macaca fascicularis). Oecologia 82, 166171.

Corlett, R.T., Primack, R.B., 2008. Tropical rainforest conservation: a global perspective. In: Carson, W.P., Schnitzer, S.A. (Eds.), Tropical Forest Community Ecology. Blackwell Science, Oxford, pp. 442-457.

da Silva, J.M.C., Uhl, C., Murray, G., 1996. Plant succession, landscape management, and the ecology of frugivorous birds in abandoned Amazonian pastures. Conserv. Biol. 10, 491-503.

Deikumah, J.P., Kudom, A.A., 2010. Biodiversity status of urban remnant forests in Cape Coast, Ghana. J. Sci. Technol. 30, 1-8.

Dirzo, R., 2001. Plant-animal interactions: lessons for our understanding of nature, and implications for biodiversity conservation. In: Press, M.C., Huntley, N.J. Levin, S. (Eds.), Ecology: Achievement and Challenge. Blackwell Science, Oxford, UK, pp. 319-355.

Dittus, W.P.J., 1977. The socioecological basis for the conservation of the toque monkey (Macaca sinica) of Sri Lanka (Ceylon). In: Rainer, P., III (Ed.), Primate Conservation. Academic Press, New York, NY, pp. 237-265.

Dittus, W.P.J., 1988. Group fission among wild toque macaques as a consequence of female resource competition and environmental stress. Anim. Behav. 36, 16261645.

Duncan, R.S., Chapman, C.A., 1999. Seed dispersal and potential forest succession in abandoned agriculture in tropical Africa. Ecol. Appl. 9, 998-1008. 
Duncan, R.S., Chapman, C.A., 2002. Limitations of animal seed dispersal for enhancing forest succession on degraded lands. In: Levey, D.J., Silva, W.R., Galetti, M. (Eds.), Seed-dispersal and Frugivory: Ecology, Evolution and Conservation. CAB International, New York, pp. 437-450.

Enstam, K.L., Isbell, L.A., 2007. The guenons (Genus Cercopithecus) and their allies behavioral ecology of polyspecific associations. In: Campbell, C.J., Fuentes, A., MacKinnon, K.C., Panger, M., Bearder, S.K. (Eds.), Primates in Perspective. Oxford University Press, Oxford, New York.

Forget, P.-M., Dennis, A.J., Mazer, S.J., Jansen, P.A., Kitamura, S., Lambert, J.E., Westcott, D.A., 2007. Seed allometry and disperser assemblages in tropical rainforests: a comparison of four floras on different continents. In: Dennis, A.J., Schupp, E.W., Green, R.J., Westcott, D. (Eds.), Seed Dispersal: Theory and its Application in a Changing World. CAB International Publishing, Wallingford, UK, pp. $5-36$.

Fukuda, F., 1989. Habitual fission-fusion and social organization of the Hakone troop of Japanese macaques in Kanagawa prefecture. Japan Int. J. Primatol. 10, 419-439.

Fukuda, F., 2004. Dispersal and environmental disturbance in japanese macaques (Macaca fuscata). Primate Report 68, 53-69.

Gautier-Hion, A., Gautier, J.P., Maisels, F., 1993. Seed dispersal versus seed predation: an inter-site comparison of two related African monkeys. Plant Ecol. 107-108, 237-244.

Gross-Camp, N., Kaplin, B.A., 2005. Chimpanzee (Pan troglodytes) seed dispersal in an Afromontane forest: microhabitat influences on the postdispersal fate of large seeds. Biotropica 37, 641-649.

Gross-Camp, N., Kaplin, B.A., 2011. Differential seed handling by two African primates affects seed fate and establishment of large-seeded trees. Acta Oecol. 37, 578-586.

Hart, J.A., Detwiler, K.M., Gilbert, C.C., Burrell, A.S., Fuller, J.L., Emetshu, M., Hart, T.B., Vosper, A., Sargis, E.J., Tosi, A.J., 2012. Lesula: a new species of Cercopithecus monkey endemic to the Democratic Republic of Congo and implications for conservation of Congo's Central Basin. PLoS ONE 7, e44271.

Hill, C.M., 2000. Conflict of interest between people and baboons: crop raiding in Uganda. Int. J. Primatol. 21, 299-315.

Hill, C.M., Webber, A.D., 2010. Perceptions of nonhuman primates in humanwildlife conflict scenarios. Am. J. Primatol. 72, 919-924.

Hill, C., Osborn, F., Plumptre, A.J., 2002. Human-Wildlife Conflict: Identifying the Problem and Possible Solutions. Wildlife Conservation Society.

Hoffman, T.S., O’Riain, M.J., 2011. The spatial ecology of chacma baboons (Papio ursinus) in a human-modified environment. Int. J. Primatol. 32, 308-328.

Holbrook, K.M., Smith, T.B., 2000. Seed dispersal and movement patterns in two species of Ceratogymna hornbills in a West African tropical lowland forest. Oecologia 125, 249-257.

Huang, C.-L., 2005. Effects of dispersal via cheek pouches of Formosan macaques (Macaca cyclopis) on seed shadow and seed fate of three Lauraceae species at Fushan experimental forest. National Taiwan University, Taipei.

Isaac, N.J.B., Cowlishaw, G., 2004. How species respond to multiple extinction threats. Proc. Royal Soc. London B 271, 1135-1141.

IUCN, 2012. IUCN Red List Categories and Criteria. Version 3.1. second ed. <http:// www.iucnredlist.org/technical-documents/categories-and-criteria/2001categories-criteria> Downloaded on 14/03/2012, p. 38, Gland, Switzerland and Cambridge, UK.

IUCN, 2013. IUCN Red List of Threatened Species. Version 2013.2. <http:// www.iucnredlist.org> Downloaded on 21/11/2013.

Johns, A.D., Skorupa, J.P., 1987. Responses of rain-forest primates to habitat disturbance: a review. Int. J. Primatol. 8, 157-191.

Kankam, B.O., Oduro, W., 2012. The effect of frugivory on postdispersal seed removal and germination in the pantropical forest tree Antiaris toxicaria Leschenault. Afr. J. Ecol. 50, 21-28.

Kaplin, B.A., Lambert, J.E., 2002. Effectiveness of seed dispersal by Cercopithecus Monkeys: implications for seed input into degraded areas. In: Levey, D.J., Silva, W.R., Galetti, M. (Eds.), Seed-Dispersal and Frugivory: Ecology, Evolution and Conservation. CABI Publishing, New York, pp. 351-364.

Kaplin, B.A., Moermond, T.C., 1998. Variation in seed handling by two species of forest monkeys in Rwanda. Am. J. Primatol. 45, 83-101.

Kinnaird, M.F., 1994. Competition for a forest palm: use of Phoenix reclinata by human and nonhuman primates. Conserv. Biol. 6, 101-107.

Kirika, J.M., 2007. Frugivores, Seed Dispersal and Tree Regeneration along a Human Disturbance Gradient in East African tropical Rainforests. Johannes GutenbergUniversität, Mainz, p. 84.

Kunz, B.K., Linsenmair, K.E., 2008. Diet and behavioural ecology of olive baboons in the Comoé National Park. Folia Primatol. 79, 31-51.

Lambert, J.E., 1998. Primate digestion: interactions among anatomy, physiology, and feeding ecology. Evol. Anthropol. 7, 8-20.

Lambert, J.E., 1999. Seed handling in chimpanzees (Pan troglodytes) and redtail monkeys (Cercopithecus ascanius): implications for understanding hominoid and cercopithecine fruit-processing strategies and seed dispersal. Am. J. Phys. Anthropol. 109, 365-386.

Lambert, J.E., 2001. Red-tailed guenons (Cercopithecus ascanius) and Strychnos mitis: evidence for plant benefits beyond seed dispersal. Int. J. Primatol. 22, 189-201.

Lambert, J.E., 2002a. Digestive retention times in forest guenons (Cercopithecus spp.) with reference to chimpanzees (Pan troglodytes). Int. J. Primatol. 23, 1169-1185.

Lambert, J.E., 2002b. Exploring the link between animal frugivory and plant strategies: the case of primate fruit processing and post-dispersal seed fate. In: Levey, D.J., Silva, W.R., Galetti, M. (Eds.), Seed-Dispersal and Frugivory: Ecology, Evolution and Conservation. CAB International, New York, pp. 365-379.
Lambert, J.E., 2005. Competition, predation, and the evolutionary significance of the cercopithecine cheek pouch: the case of Cercopithecus and Lophocebus. Am. J. Phys. Anthropol. 126, 183-192.

Lambert, J.E., 2010. Primate seed dispersers as umbrella species: a case study from Kibale National Park, Uganda, with implications for Afrotropical forest conservation. Am. J. Primatol. 71, 1-16.

Lambert, J.E., Garber, P.A., 1998. Evolutionary and ecological implications of primate seed dispersal. Am. J. Primatol. 45, 9-28.

Lambert, J.E., Whitham, J.C., 2001. Cheek pouch use in Papio cynocephalus. Folia Primatol. 72, 89-91.

Laurance, W.F., Croes, B.M., Tchignoumba, L., Lahm, S.A., Alonso, A., Lee, M.E., Campbell, P., Ondzeano, C., 2006. Impacts of roads and hunting on central African rainforest mammals. Conserv. Biol. 20, 1251-1261.

Lee, P.C., Priston, N.E.C., 2005. Human attitudes to primates: perceptions of pests, conflict and consequences for primate conservation. In: Commensalism and conflict: the human primate interface. Hignell Printing, Winnepeg, pp. 1-23.

Lucas, P.W., Corlett, R.T., 1998. Seed dispersal by long-tailed macaques. Am. J. Primatol. 45, 29-44.

Maisels, F., Ambahe, R., Ambassa, E., Fotso, R., 2006. New northwestern range Limit of the northern talapoin, Mbam et Djerem National Park, Cameroon. Primate Conserv. 21, 89-91.

Marini, L., Bruun, H.H., Heikkinen, R.K., Helm, A., Honnay, O., Krauss, J., Kühn, I., Lindborg, R., Pärtel, M., Bommarco, R., 2012. Traits related to species persistence and dispersal explain changes in plant communities subjected to habitat loss. Divers. Distrib. 18, 898-908.

Markl, J.S., Schleuning, M., Forget, P.-M., Jordano, P., Lambert, J.E., Traveset, A., Wright, S.J., Böhning-Gaese, K., 2012. Meta-analysis of the effects of human disturbance on seed dispersal by animals. Conserv. Biol. 26, 1072-1081.

McConkey, K.R., Brockelman, W.Y., 2011. Non-redundancy in the dispersal network of a generalist tropical forest tree. Ecology 92, 1492-1502.

McConkey, K.R., Prasad, S., Corlett, R.T., Campos-Arceiz, A., Brodie, J.F., Rogers, H., Santamaria, L., 2012. Seed dispersal in changing landscapes. Biol. Conserv. 146, $1-13$.

McFarland, R., Majolo, B., 2011. Exploring the components, asymmetry and distribution of relationship quality in wild Barbary macaques (Macaca sylvanus). PLOS ONE 6, e28826.

Menon, S., Poirier, F.E., 1996. Lion-tailed macaques (Macaca silenus) in a disturbed forest fragment: activity patterns and time budget. Int. J. Primatol. 17, 969-985. Muller-Landau, H.C., 2007. Predicting the long-term effects of hunting on plant species composition and diversity in tropical forests. Biotropica 39, 372-384.

Murray, P., 1975. The role of cheek pouches in cercopithecine monkey adaptative strategy. In: Tuttle, R.H. (Ed.), Primate Functional Morphology and Evolution. Mouton, The Hague, pp. 151-194.

Mworia, J.K., Kinyamario, J.I., Omari, J.K., Wambua, J.K., 2011. Patterns of seed dispersal and establishment of the invader Prosopis juliflora in the upper floodplain of Tana River, Kenya. Afr. J. Range Forage Sci. 28, 35-41.

Nakashima, Y., Lagan, P., Kitayama, K., 2008. A study of fruit-frugivore interactions in two species of Durian (Durio, Bombacaceae) in Sabah, Malaysia. Biotropica 40, 255-258.

Nathan, R., Muller-Landau, H.C., 2000. Spatial patterns of seed dispersal, their determinants and consequences for recruitment. Trends Ecol. Evol. 15, 278285.

Naughton-Treves, L., 1998. Predicting patterns of crop damage by wildlife around Kibale National Park, Uganda. Conserv. Biol. 12, 156-168.

Oates, J.F., 1987. Food distribution and foraging behavior. In: Smuts, B.B., Cheney, D.L., Seyfarth, R.M., Wrangham, R.W., Struhsaker, T.T. (Eds.), Primate Societies. University of Chicago Press, Chicago, pp. 197-209.

O'Brien, T.G., Kinnaird, M.F., 1997. Behavior, diet, and movements of the Sulawesi crested black macaque (Macaca nigra). Int. J. Primatol. 18, 321-351.

Otani, T., 2010. Seed dispersal by Japanese macaques, In: N. Nakagawa, M. Nakamichi, H. Sugiura (Eds.), The Japanese macaques, Tokyo, Japan, pp. 129142 .

Poulsen, J.R., Clark, C.J., Smith, T.B., 2001. Seed dispersal by a diurnal primate community in the Dja Reserve, Cameroon. J. Trop. Ecol. 17, 787-808.

Poulsen, J.R., Clark, C.J., Connor, E.F., Smith, T.B., 2002. Differential resource use by primates and hornbills: implications for seed dispersal. Ecology 83, 228-240.

Pringle, E.G., Álvarez-Loayza, P., Terborgh, J., 2007. Seed characteristics and susceptibility to pathogen attack in tree seeds of the Peruvian Amazon. Plant Ecol. 193, 211-222.

Priston, N.E.C., 2005. Crop-raiding by Macaca Ochreata Brunnescens in Sulawesi: Reality, Perceptions and Outcomes for Conservation. University of Cambridge, Cambridge.

Ram, S., Venkatachalam, S., Sinha, A., 2003. Changing social strategies of wild female bonnet macaques during natural foraging and on provisioning. Curr. Sci. 84, 780-790.

Reinhardt, C.F., Rossouw, L., 2000. Ecological adaptation of an alien invader plant (Opuntia stricta) determines management strategies in the Kruger National Park. J. Plant Diseases Protect. 17, 77-84.

Richard, A.F., Goldstein, S.J., Dewar, R.E., 1989. Weed macaques: the evolutionary implications of macaque feeding ecology. Int. J. Primatol. 10, 569-594.

Riley, E.P., 2007. The human-macaque interface: conservation implications of current and future overlap and conflict in Lore Lindu National Park, Sulawesi, Indonesia. Am. Anthropol. 109, 473-484.

Riley, E.P., Priston, N.E.C., 2010. Macaques in farms and folklore: exploring the human-nonhuman primate interface in Sulawesi, Indonesia. Am. J. Primatol. 71, $1-7$. 
Riley, E.P., Wolfe, L.D., Fuentes, A., 2011. Ethnoprimatology: contextualizing human and nonhuman primate interactions. In: Campbell, C.J., Fuentes, A., MacKinnon, K.C., Panger, M., Bearder, S.K. (Eds.), Primates in perspective. Oxford University Press, New York, pp. 676-686.

Rowe, N., Myers, M., 2011. All the World's Primates. www.alltheworldsprimates.org. Primate Conservation Inc. Charlestown RI. Downloaded on 10/10/2011.

Saj, T.L., Sicotte, P., Paterson, J.D., 2001. The conflict between vervet monkeys and farmers at the forest edge in Entebbe, Uganda. Afr. J. Ecol. 39, 195-199.

Sargis, E.J., Terranova, C.J., Gebo, D.L., 2008. Evolutionary morphology of the guenon postcranium and its taxonomic implications. In: Sargis, E.J. (Ed.), Mammalian Evolutionary Morphology: A Tribute to Frederick S. Szalay. Springer-Verlag New York Inc., New York, pp. 361-372.

Schupp, E.W., Jordano, P., Gómez, J.M., 2010. Seed dispersal effectiveness revisited: a conceptual review. New Phytol. 188, 333-353.

Seth, P.K., Chopra, P.K., Seth, S., 2001. Indian rhesus macaque: habitat, ecology and activity patterns of naturally occurring populations. In: Gupta, A.K. (Ed.), Nonhuman Primates of India, ENVIS Bulletin: Wildlife \& Protected Areas. Wildl Inst India, Dehradun (India), pp. 68-80.

Sethi, P., Howe, H.F., 2009. Recruitment of hornbill-dispersed trees in hunted and logged forests of the Indian Eastern Himalaya. Conserv. Biol. 23, 710-718.

Sha, J.C.M., Gumert, M.D., Lee, B.P.Y.H., Fuentes, A., Rajathurai, S., Chan, S., JonesEngel, Lisa., 2009. Status of the long-tailed macaque Macaca fascicularis in Singapore and implications for management. Biodiv. Conserv. 18, 2909-2926.

Sillero-Zubiri, C., Switzer, D., 2001. Crop raiding primates: Searching for alternative, humane ways to resolve conflict with farmers in Africa. People and Wildlife Initiative. Wildlife Conservation Research Unit, Oxford University.

Singh, M., Vinathe, S., 1990. Inter-population differences in the time budgets of bonnet monkeys (Macaca radiata). Primates 31, 589-596.

Singh, M., Singh, M., Kumar, M.A., Kumara, H.N., Sharma, A.K., Kaumanns, W., 2002. Distribution, population structure, and conservation of lion-tailed macaques (Macaca silenus) in the Anaimalai Hills, Western Ghats, India. Am. J. Primatol. 57, 91-102.

Slater, K., du Toit, J.T., 2002. Seed dispersal by chacma baboons and syntopic ungulates in southern African savannas. South African J. Wildlife Res. 32, 75-79.

Smith, L.W., Link, A., Cords, M., 2008. Cheek pouch use, predation risk, and feeding competition in blue monkeys (Cercopithecus mitis stuhlmanni). Am. J. Phys. Anthropol. 137, 334-341.

Stickler, C.M., 2004. The Effects of Logging on Primate-Habitat Interactions: A Case Study of Redtail Monkeys (Cercopithecus ascanius) in Kibale National Park Uganda. University of Florida, Gainesville, FL, p. 94.

Stoner, K.E., Riba-Hernández, P., Vulinec, K., Lambert, J.E., 2007. The role of mammals in creating and modifying seedshadows in tropical forests and some possible consequences of their elimination. Biotropica 39, 316-327.

Strum, S.C., 2010. The development of primate raiding: implications for management and conservation. Int. J. Primatol. 31, 133-156.

Swart, J., Lawes, M.J., 1996. The effect of habitat patch connectivity on samango monkey (Cercopithecus mitis) metapopulation persistence. Ecol. Model. 93, 5774.

Thomas, S.C., 1991. Population densities and patterns of habitat use among anthropoid primates of the Ituri Forest, Zaire. Biotropica 23, 68-83.
Traveset, A., Verdú, M., 2002. A meta-analysis of the effect of gut treatment on seed germination. In: Levey, D.J., Silva, W.R., Galetti, M. (Eds.), Seed Dispersal and Frugivory: Ecology, Evolution and Conservation. CAB International, New York, pp. 339-350.

Tsuji, Y., 2011. Seed dispersal by Japanese macaques (Macaca fuscata) in western Tokyo, central Japan: a preliminary report. Mammal Study 36, 165-168.

Tsujino, R., Yumoto, T., 2009. Topography-specific seed dispersal by Japanese macaques in a lowland forest on Yakushima Island, Japan. J. Anim. Ecol. 78, $119-125$.

Tutin, C.E.G., Williamson, E.A., Rogers, M.E., Fernandez, M., 1991. A case study of a plant-animal relationship: Cola lizae and lowland gorillas in the Lopé Reserve. Gabon. J. Trop. Ecol. 7, 181-199.

Tutin, C.E.G., White, L.J.T., Mackanga-Missandzou, A., 1997. The use by rain forest mammals of natural forest fragments in an Equatorial African savanna. Conserv. Biol. 11, 1190-1203.

Twinomugisha, D., Chapman, C.A., Lawes, M.J., O’Driscoll Worman, C., Danish, L.M., 2006. How does the golden monkey of the Virungas cope in a fruit scarce environment? In: Newton-Fisher, N.E., Notman, H., Reynolds, V., Paterson, J.D (Eds.), Primates of Western Uganda. Springer, New York, pp. 45-60.

Vulinec, K., Lambert, J.E., Mellow, D.J., 2006. Primate and dung beetle communities in secondary growth rain forests: implications for conservation of seed dispersal systems. Int. J. Primatol. 27, 855-879.

Warren, Y., 2008. Crop-raiding baboons (Papio anubis) and defensive farmers: a West African perspective. West African J. Appl. Ecol. 14, 1-11.

Warren, Y., Higham, J.P., Maclarnon, A.M., Ross, C., 2011. Crop-raiding and commensalism in Olive baboons: the costs and benefits of living with humans. In: Sommer, V., Ross, C. (Eds.), Primates of Gashaka - Developments in Primatology: Progress and Prospects. Springer Science/Business Media, UK pp. 307-332.

Weyher, A.H., Ross, C., Semple, S., 2006. Gastrointestinal parasites in crop raiding and wild foraging Papio anubis in Nigeria. Int. J. Primatol. 27, 1519-1534.

Wieczkowski, J., 2005. Comprehensive conservation profile of Tana mangabeys. Int. J. Primatol. 26, 651-660.

Wilson, D.E., Reeder, D.M., 2005. Mammal species of the world. A taxonomic and geographic reference, third ed. Johns Hopkins University Press.

Woodroffe, R., Thirgood, S., Rabinowitz, A., 2005. The impact of human-wildlife conflict on natural systems. In: Woodroffe, R., Thirgood, S., Rabinowitz, A. (Eds.), People and Wildlife: Conflict or Coexistence? Cambridge University Press, Cambridge.

Worman, C.O., Chapman, C.A, 2006. Densities of two frugivorous primates with respect to forest and fragment tree species composition and fruit availability. Int. J. Primatol. 27, 203-225.

Yasuda, M., Miura, S., Ishii, N., Okuda, T., Hussein, N.A., 2005. Fallen fruits and terrestrial vertebrate frugivores: a case study in a lowland tropical rainforest in peninsular Malaysia. In: Forget, P.-M., Lambert, J.E., Hulme, P.E., Vander Wall S.B. (Eds.), Seed Fate: Predation, Dispersal and Seedling Establishment. CAB International, Cambridge, pp. 151-174.

Yumoto, T., Noma, N., Maruhashi, T., 1998. Cheek-pouch dispersal of seeds by Japanese monkeys (Macaca fuscata yakui) on Yakushima Island, Japan. Primates $39,325-338$. 